dealing with economic and financial crises that have an adverse impact on population mental health.

1 Royal College of Psychiatrists. No Health without Public Mental Health: The Case for Action (Position Statement PS4/2010). Royal College of Psychiatrists, 2010

2 Bhui K, Dinos S. Preventive psychiatry: a paradigm to improve population mental health and well-being. Br J Psychiatry 2011; 198: 417-9.

3 Saul L. Preventive psychiatry. Proc Am Philos Soc 1949; 93: 330-4.

4 Bousquet J, Anot JM, Sterk P, Adcock IM, Chung KF, Roca J, et al. Systems medicine and integrated care to combat chronic non-communicable diseases. Genome Med 2011; 3: 43.

5 Collins PY, Patel V, Joestl SS, March D, Insel TR, Daar AS, et al (2011) Grand challenges in global mental health. Nature 2011; 475: 27-30.

6 Lemkau P. Preventive psychiatry: its application to general practice and by health agencies. South Med J 1954; 47: 498-505.

7 Madhussodanam S. Preventive psychiatry: we are getting closer to fulfilling the promise of reducing mental illness. Ann Clin Psychiatry 2010; 22: 217-8.

Kamaldeep Bhui, Wolfson Institute of Preventive Medicine, Centre for Psychiatry, Queen Mary University of London. Email: k.s.bhui@qmul.ac.uk; Sokratis Dinos, Wolfson Institute of Preventive Medicine, Queen Mary University of London, UK

doi: $10.1192 /$ bjp.199.4.340a

\section{Homicide rates and income inequality}

There is evidence that psychosocial factors other than those discussed by Swinson et al ${ }^{1}$ affect homicide rates and it is important to know whether these disproportionately affect individuals diagnosed as mentally ill. Specifically, there is evidence that income inequality strongly influences rates of violent crime, including homicide. ${ }^{2}$ Wilkinson \& Pickett have claimed that changes in inequality also influence rates of substance misuse. ${ }^{3}$ It is thus important to know whether the increase in homicide rates described by Swinson et al could be caused by those with psychiatric problems being 'left further behind' in terms of income and/or social status.

1 Swinson N, Flynn SM, While D, Roscoe A, Kapur N, Appleby L, et al. Trends in rates of mental illness in homicide perpetrators. Br J Psychiatry 2011; 198 : 485-9.

2 Wilkinson R. Why is violence more common where inequality is greater? Ann NY Acad Sci 2004; 1036: 1-12.

3 Wilkinson R, Picket K. The Spirit Level: Why Equality is Better for Everyone. Penguin, 2010.

Michael Moutoussis, 30 Melrose Avenue, Potters Bar, Herts EN6 1TA, UK. Email: fzsemmo@gn.apc.org

doi: 10.1192/bjp.199.4.341

Authors' reply: We were looking for factors which corresponded to the overall rise in homicides in people with psychosis; factors which showed increases of a similar magnitude, over a similar timescale. This was the case for drug misuse, allowing us to infer an association. Evidence has been found linking income inequality to both violent crime ${ }^{1}$ and rates of substance misuse, ${ }^{2}$ although this has been disputed and there is controversy ${ }^{3}$ over the validity of the association found between income inequality and mental illness. ${ }^{4}$ There has been a marked increase in income inequality in recent years ${ }^{5}$ but, from the data which we have available to us, we are unable to comment as to whether this is also the case among those with mental illness, and whether there is any causal association with homicide rates. In future research we hope to explore the data using deprivation indices which might provide further information on any association between income inequality, mental illness and homicide.
1 Wilkinson R. Why is violence more common where inequality is greater? Ann NY Acad Sci 2004; 1036: 1-12.

2 Wilkinson R, Picket K. The Spirit Level: Why Equality is Better for Everyone. Penguin, 2010.

3 Pickett KE, James OW, Wilkinson RG. Income inequality and the prevalence of mental illness: a preliminary international analysis. J Epidemiol Community Health 2006; 60: 646-7.

4 Huisman $\mathrm{M}$, Avendano M. Income inequality and the prevalence of mental illness: the "outlier" US drives the association (e-letter). J Epidemiol Community Health 2006; 26 September.

5 Davey Smith G, Dorling D, Mitchell R, Shaw M. Health inequalities in Britain: continuing increases up to the end of the 20th Century. J Epidemiol Community Health 2002; 56: 434-5.

Nicola Swinson, National Confidential Inquiry into Suicide and Homicide by People with Mental Illness, Centre for Suicide Prevention, University of Manchester, UK. Email: nicola.swinson@btopenworld.com; Sandra M. Flynn, David While, Alison Roscoe, Navneet Kapur, Louis Appleby, Jenny Shaw, National Confidential Inquiry into Suicide and Homicide by People with Mental IIIness, Centre for Suicide Prevention, University of Manchester, UK

doi: 10.1192/bjp.199.4.341a

\section{Observational BALANCE}

We read with interest Kessing et al's timely and welcome paper ${ }^{1}$ supporting, by way of observational cohort study, the findings of BALANCE. ${ }^{2}$ Lithium again is shown to be superior to valproate for the management of bipolar disorder. The strength in this case comes from bridging the gap between the relatively brief follow-up in randomised control trials (RCTs) and the real-life situation faced by clinicians managing a lifelong illness of unpredictable course. Although the enriched study design in BALANCE aimed to maximise the generalisability of the findings to a clinical population, limitations inevitably remained in terms of including patients who had shown a differential previous response to either lithium or valproate, diagnostic heterogeneity within the sample population, and frequency of comorbidity compared with the general population. The limitations of observational cohort studies are multiple and well documented. One key concern is confounding by indication, but more general problems exist with group biases and masking of cause and effect relationships.

Kessing et al used 'switch to' and 'add on' as proxy outcomes for the efficacy of mood stabilisers. It would have been interesting, if possible, to separate the 'switch to' group from the 'add on' groups. The 'add on' outcome probably represents a treatment failure; however 'switch to' is likely to be a combination of lack of efficacy and poor tolerability. Indeed, their findings suggest that the initial, very rapid increase in incidence of switch/add on is related to tolerability rather than efficacy, whereas in BALANCE this finding would have been lost by drop-out during the run-in period. This is unlikely, however, to explain the superiority of lithium that is clearly present in both outcome measures.

It was previously argued that observational studies would overestimate treatment effects and that they hold little value in assessing therapies; however, comparative studies with RCTs, across various branches of medicine have now dismissed this. ${ }^{3}$ This sort of complementary approach, reconfirming findings from RCTs over long follow-up periods, is an important addition to the evidence base for treatment. This is especially true in areas where the disorder under investigation is chronic relapsing-remitting, and when the exclusion criteria of RCTs can often mean that external validity is low. If, as has been suggested, bipolar disorder is a heterogeneous condition with subtypes associated with preferential response to specific mood stabilisers ${ }^{4}$ (which can be identified by symptoms, clinical course and family history), then the observational study carries even more weight when compared with the RCT as it 'allocates' patients to treatments on the basis of 